\title{
American Meteorological Society Order Form for Publications Advertised in This Issue
}

Name:

$\square$ Member

Address:

City, State: ZIP:

Province:

Country:

21st Conf. on Hurricanes and Tropical Meteorology (p. 2154)

AMS Silk Ties and Scarves (p. 2170)

1994 Curricula in the Atmospheric ... and Related Sciences (p. 2210)

Fourth Symposium on Education (p. 2233)

AMS Umbrellas (p. 2342)

*All prices include shipping and handling, and are subject to change without notice.

Please send prepaid orders to:

Please include with my order:
$\square$ An AMS membership application
$\square$ A complete AMS price list
$\square$ A WMO catalogue

$\square$ Nonmember

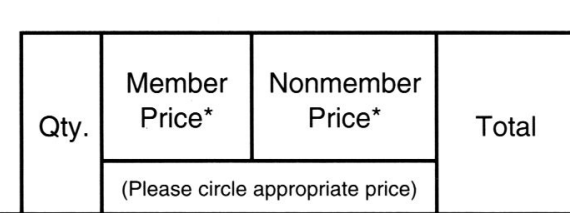

\begin{tabular}{|l|l|l|l|l|} 
& & $\$ 35.00$ & $\$ 50.00$ & \\
\hline & 1 & $\$ 15.00$ & $\$ 15.00$ & \\
\hline & & & &
\end{tabular}

\begin{tabular}{|l|l|l|l|}
2 & $\$ 25.00$ & $\$ 25.00$ & \\
\hline & $\$ 30.00$ & $\$ 40.00$ & \\
\hline & & &
\end{tabular}

(p. 2210$)$

\begin{tabular}{l|l}
$\$ 35.00$ & $\$ 50.00$ \\
\hline
\end{tabular}

\begin{tabular}{l|l}
$\$ 12.00$ & $\$ 12.00$ \\
\hline
\end{tabular}

